\title{
Study of the Physical, Mechanical and Thermal Properties of Banana Fiber Reinforced HDPE Composites
}

\author{
Budrun Neher ${ }^{*}$, Rakib Hossain'2, Kaniz Fatima1, M. A. Gafur ${ }^{3}$, Md. Abul Hossain', Farid Ahmed1 \\ ${ }^{1}$ Department of Physics, Jahangirnagar University, Dhaka, Bangladesh \\ ${ }^{2}$ Department of Physics, Bangabandhu Sheikh Mujibur Rahman Science \& Technology University, Gopalganj, Bangladesh \\ ${ }^{3} \mathrm{PP}$ and PDC, Bangladesh Council of Scientific and Industrial Research, Dhaka, Bangladesh \\ Email: `budrunneher@gmail.com,bnmanaf@yahoo.com
}

How to cite this paper: Neher, B., Hossain, R., Fatima, K., Gafur, M.A., Hossain, Md.A. and Ahmed, F. (2020) Study of the Physical, Mechanical and Thermal Properties of Banana Fiber Reinforced HDPE Composites. Materials Sciences and Applications, 11, 245-262.

https://doi.org/10.4236/msa.2020.114017

Received: January 24, 2020

Accepted: April 10, 2020

Published: April 13, 2020

Copyright $\odot 2020$ by author(s) and Scientific Research Publishing Inc. This work is licensed under the Creative Commons Attribution International License (CC BY 4.0).

http://creativecommons.org/licenses/by/4.0/

\begin{abstract}
Natural fiber reinforced composite materials are replacing the conventional materials, owing to their excellent physical, mechanical, electrical, and thermal properties. Also they increase biodegradability, reduce cost and decrease environmental pollution and hazards. In this study, obsolete high density polyethylene (HDPE) has used as polymer matrix and banana fiber as reinforcement material. Composites (5\%, 10\%, $15 \%$ and $20 \%$ of fiber contents) were made by hot press molding method by using Paul-Otto Weber Hydraulic press machine. The physical, mechanical and thermal properties of banana fiber-HDPE composites were studied and investigated the increment or decrement nature of different properties due to addition of banana fiber in BF-HDPE composites. The bulk density of composites increased with the increase wt. (\%) of fiber content in composites. Water absorption ability of banana fiber and BF-HDPE composites also increased with the increase of wt. (\%) of fiber content in composites and with socking time. Tensile strength of the BF-HDPE composites increased with the increase of fiber content in both cases (continuous aligned fiber orientation and continuous bidirectional fiber orientation). Moreover, the tensile strength of BF-HDPE composites with continuous aligned fiber orientation was greater than that of continuous bidirectional fiber orientation. At first, the flexural strength increased for 5\% BF-HDPE composites then the value decreased for other higher compositions. The flexural strength of continuous aligned fiber orientation was slightly greater than that of continuous bidirectional fiber orientation and composite with $5 \%$ banana fiber showed better flexural properties than others. Leeb's rebound hardness decreased with the increase of fiber addition. Different thermal properties like TG/DTG, DTA of the obsolete HDPE and
\end{abstract}


BF-HDPE composites were studied using thermo gravimetric analyzer and it was found that composite with $20 \%$ fiber content was more thermally stable than three other compositions.

\section{Keywords}

BF-HDPE, Water Absorption, Tensile Strength, Hardness, TG-DTG

\section{Introduction}

Composite materials are the material produced by the combination of two or more individually different materials which show superior properties from their constituent materials. The constituents of the substances work together to make the composite a superior material compared to the individual constituents. In recent years, composite materials are being widely used due to their excellent properties such as light weight, high strength, environment friendly applications, etc. [1]. In case of composite material, one or more discontinuous phase known as reinforcement is inserted in a continuous phase known as matrix. Reinforcement materials are harder and stronger than matrix. Usually matrix materials are metallic, polymeric or ceramic. Reinforcement material can be fiber or particle and also fiber can be synthetic or natural. The strong fibers are bounded by a fragile matrix material. As the reinforcement is generally much stronger and stiffer than the matrix so it gives the composites different good properties. This is because the reinforcements are usually discontinuous, the matrix helps to transfer load among the reinforcement.

In case of structural and engineering materials, fiber reinforced composites have been broadly used from recent few decades. To produce fiber reinforced polymer composite synthetic or natural fiber used as discontinuous phase and polymer used as continuous phase, common synthetic fiber like glass, carbon, aramid has been often used in aerospace industries due to their low density, high stiffness and high strength properties [2] [3]. Although synthetic fiber possesses some very good properties, they are not good enough for biodegradability, recyclability, initial processing cost and health hazards compared to natural fiber [3]. In that case natural fibers are a promising candidate to replace these synthetic fibers for environmental concern. Natural fibers like jute, banana, sisal, hemp etc. show some fascinating properties such as lightweight, environmental friendly, low cost, high flexibility, renewability, high specific strength, biodegradability, high toughness, and easy processing [4] [5] [6] [7]. Recently various types of natural fibers such as palm, wood, bamboo, sugarcane, banana etc. have been studied for using in plastic [8]. Different types of cellulosic fiber such as sisal, coir, jute, bamboo etc. have already been used in various thermosetting and thermoplastic resins [9]-[15].

Plastic product is being a very essential part in our everyday life which making huge plastic waste. So it is very important to solve this plastic waste problem by 
proper scientific research and to make environment friendly composite material for our everyday usage which is simply bio assimilated and bio degradable [16]. Natural fibers show good specific strength, economic viability, low density, superior energy recovery and good biodegradability which make it better candidate over glass fiber in composite material industry [17]. For that reason, natural fiber-reinforced composites have drawn much more attention for engineering, automobile, infrastructure, aerospace and other cutting edge technology [18].

Various properties of natural fiber-reinforced composites have already been investigated by a lot of research group all over the world. A study was done by R. Chianelli et al. on mechanical characterization of thermo-mechanical recycling of composites based on recycled HDPE from post-consumed motor-oil plastic containers as matrix and sisal fibers as reinforcement [19]. The sisal fibers do not contribute to increase tensile strength. As fiber content increases, loss of ductility is observed. Ibrahim et al. carried out an investigation on Lignocellulosic composites by using various types of adhesives [20]. Best mechanical properties were found for the incorporation of sawdust-urea-formaldehyde resin into banana fiber and proper adhesion-fiber interaction is believed to the reason for the performance. Woven natural fiber reinforced unsaturated polyester resin composites were studied by Rafia Akter and her co-workers [8]. Woven natural fiber reinforced polymer composites consisting of Pati bet also known as murta (Clinogynedichotoma) reinforcement, unsaturated polyester resin (UPR) matrix and talc filler were fabricated by simple cold press molding. It was observed that flexural strength and modulus increased with an increase in talc content. Thermal stabilities of composites were also improved. Mubarak A. Khan et al. found that the fiber loading greatly influenced thermal stability of the resulting composites and the 50 mass \% jute containing composites possess excellent thermal properties [21]. Eleftheria et al. found that while for lower hemp concentrations the compatibilizer further reduced the thermal stability of the composites, and for the highest concentration, it resulted in a notable enhancement [22]. Florin et al. studied the physical and thermal characteristics of some cellulose fabrics as reinforced materials for composite [23]. They found that the flax and hemp fibers show one main peak of degradation, while the jute fiber shows two peaks. This may be due to the different chemical composition of the fibers, namely the fact that the jute fiber has a much higher content in lignin, which makes the degradation to arise in more stages. Hatakeyama et al. performed the thermo-gravimetric study on wood powder-filled polyurethane composites derived from lignin and found that thermal decomposition of composites is in two stages. Naznin et al. showed that from TG analysis the urea addition in ST/PVA/Ac-based film increased the thermal decomposition, which indicates the lowering of thermal stability [24].

In the present research, obsolete High density polyethylene (HDPE) has been used which is one of the highly requested plastic in the world and common plastic waste. Also HDPE is thermoplastic polymer having low water absorption and high hardness and strength. Recycling is the best way for reduce plastic solid 
waste in the environment and reducing carbon footprint [25]. It is defined by a density of greater or equal to $0.941 \mathrm{~g} / \mathrm{cm}^{3}$. According to ASTM D638 the ultimate tensile strength of HDPE is about $31 \mathrm{MPa}$. For HDPE the melting point is typically in the range $120^{\circ} \mathrm{C}$ to $180^{\circ} \mathrm{C}\left(248\right.$ to $\left.356^{\circ} \mathrm{F}\right)$ [26]. In this research, banana fiber is used because banana fiber is a lignocellulosic fiber, which is obtained from the edible-fruit-bearing plant that grows abundantly everywhere in Bangladesh also all over the world, species Musa cavendishi and Musa sapientum [27]. The objective of the present study is to observe the physical (bulk density and water absorption) and the mechanical (tensile strength, flexural stress and Leeb's rebound hardness) properties also the effect of fiber loading (mass\% of fiber) in Banana Fiber-HDPE composites on thermal properties (TG-DTG, and DTA) using thermogravimetric analyzer.

\section{Materials and Methods}

\subsection{Sample Collection}

Banana fibers were collected from banana trees grown at local area of Savar near Dhaka in Bangladesh. The fibers were mainly collected from the stem of the tree. The stems were cut from the banana tree and chopped into $6-8 \mathrm{~cm}$ in length. Chopped stems were kept in water for 20 days. After that the rotten materials were washed and fibers were collected as shown in Figure 1(a) and dried under sunlight. Then the fibers were kept at $50^{\circ} \mathrm{C}$ for 24 hours for partial removal of moisture. Obsolete HDPE was collected as the plastic bottles (called gallon bottles in US) from local market of old Dhaka in Bangladesh as shown in Figure 1 (b) [28].

\subsection{Composite Preparation}

At first the banana fiber was cut into $5 \mathrm{~cm}$ length in size. These fibers were dried at $50^{\circ} \mathrm{C}$ in dryer for 24 hours. The obsolete HDPE gallon bottles were cut into 5 $\mathrm{cm} \times 5 \mathrm{~cm}$ in size. The banana fiber and HDPE were put into Paul-Otto Weber Hydraulic press machine. A typical mold employed for compression molding.

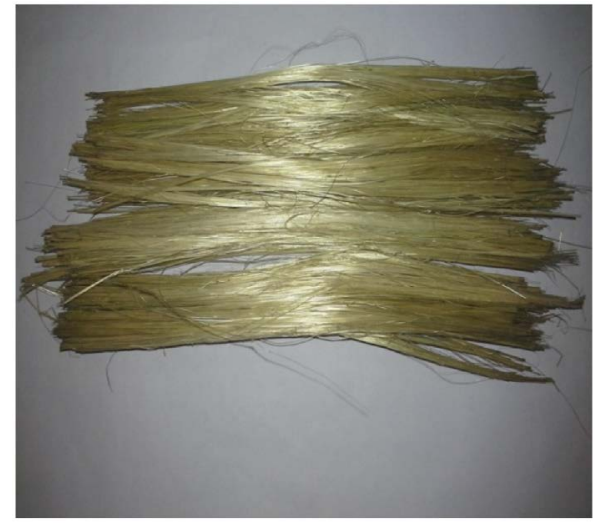

(a)

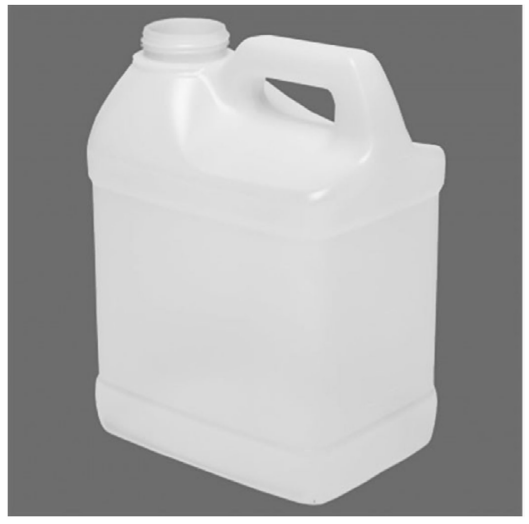

(b)

Figure 1. Photograph of (a) processed banana fiber (b) HDPE gallon bottles. 
The mold is made of two halves-the upper and the lower halves. In this case, the lower half contains a cavity when the mold is closed. The gap between the projected upper half and the cavity in the lower one gives the shape of the molded composite. As the cavity was $5 \mathrm{~cm} \times 5 \mathrm{~cm}$ the composite found was as that size. The fiber and HDPE was heated at $160^{\circ} \mathrm{C}$ and compressed at pressure $80 \mathrm{KN}$ in the mold. After completion of heating, the mold was allowed to cool down. When cooling was completed the cold mold was then demolded by hand and it became composite. Four sets of composites samples (with 5\%, 10\%, 15\% and $20 \%$ fiber content) were prepared to carry out this research.

\subsection{Composite Characterization}

\subsubsection{Physical Properties of the Composites}

\section{1) Bulk Density of Composites}

The bulk density of the composite materials have determined according to ASTM C134-76 by measuring the weight and dimensions of the respective samples using Equation (1) [29].

$$
\text { Bulk density, } D=\frac{W_{t}}{L \times W \times H}
$$

where, $W_{t}=$ Weight of the sample, $L=$ Length of the sample, $W=$ Width of the sample, $H=$ Height of the sample.

\section{2) Water Absorption Property of Banana Fiber and Composites}

Water absorption test was carried out according to ASTM D570-98 [30]. Water absorption ability of banana fiber was measured by soaking the fiber in a glass beaker and banana fiber-HDPE (BF-HDPE) composites was measured by soaking the samples in four glass beakers (for $5 \%, 10 \%, 15 \%$ and $20 \%$ ) of water at $25^{\circ} \mathrm{C}$ for different time periods (up to 168 hours). The weight of the samples was determined before ablution of the sample in water. After certain periods of time as 1, 2, 24, 48, 72 and 168 hours, samples were taken out of the water, wiped the samples using tissue paper and then measured the weight. The water uptake (mass gained) was determined as the difference of initial weight from final weight. The water soaking percentage was determined by using the following formula [31]

$$
W_{g}=\frac{W_{a}-W_{o}}{W_{o}} \times 100
$$

where $W_{a}$ and $W_{o}$ are the weight of the sample after and before soaking in water.

\subsubsection{Mechanical Properties of the Composite}

\section{1) Tensile and Flexural Property of Composite}

A universal testing machine (Hounsfield UTM 10 KN; ASTM D 3039/D 3039 M-00) [32] was used to measure the tensile strength and Young's modulus of the samples at a crosshead speed of $2 \mathrm{~mm} / \mathrm{min}$, keeping a gauge length of $50 \mathrm{~mm}$. Flexural strength also measured by the same apparatus [33]. All the samples were kept at $50^{\circ} \mathrm{C}$ for 24 hours before testing. 


\section{2) Hardness of Composite}

Hardness of a material is the resistance to deformation or indentation when a force is applied. Macroscopic hardness is generally described by strong intermolecular bonds, but the manner of solid materials under force is complex. There are different types of hardness test available-Rockwell, Brinell, Vicker's and Leeb's Rebound hardness. In this research, Leeb's Rebound hardness was investigated. The portability of Leeb's tester can sometimes help to achieve higher testing rates without destruction of samples, which in most of the case thus simplifies process and saves cost [34].

\subsubsection{Thermogravimetric and Differential Thermal Analysis (TG-DTA)}

Thermo-gravimetric (TG) analysis is a process in which variations in physical and chemical properties of materials are determined as a function of temperature [35]. Physical properties such as second-order phase transitions, sublimation, absorption and desorption etc. and chemical phenomena such as chemisorptions, desolvation, decomposition, solid-gas reactions etc. can be investigated by (TG) analysis [35]. Differential thermal analysis (DTA) is a thermo-analytic technique where the material under study and an inert reference are made to undergo identical thermal cycles, while recording any temperature difference between sample and reference [36]. This differential temperature is then plotted against time, or against temperature. Changes in the sample can be detected relative to the inert reference. Then DTA curve delivers data on the changes that have occurred such as crystallization, melting, sublimation, etc.

\section{Results and Discussion}

\subsection{Physical Properties}

\subsubsection{Bulk Density of Composites}

The effect of addition of different wt. (\%) of banana fiber on bulk density in BF-HDPE composites with continuous aligned fiber orientation samples is shown in Figure 2. The bulk density of the composites increased with the increase of fiber addition in the samples. As fiber density is higher than HDPE, so the density of composite increased.

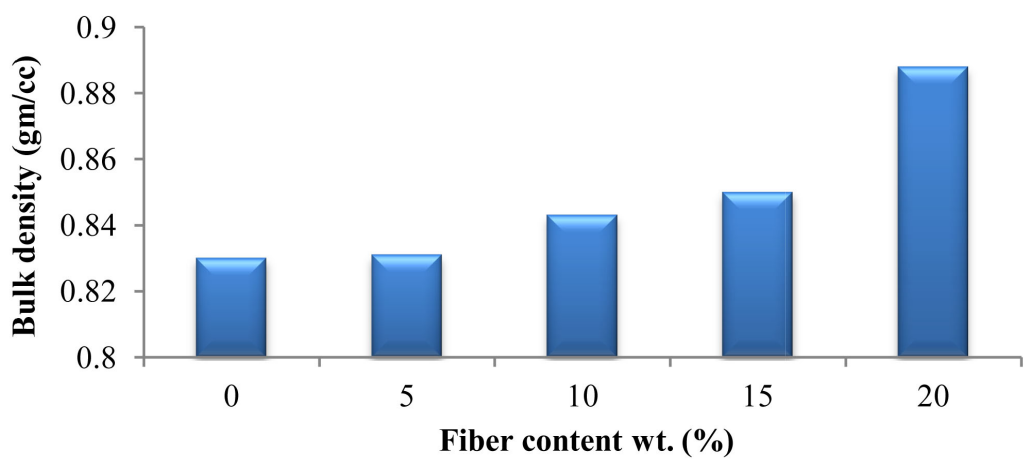

Figure 2. Effect of addition of fiber content on bulk density in BF-HDPE composites in case of continuous aligned fiber orientation. 


\subsubsection{Water Absorption of Banana Fiber}

Average water absorption ability of banana fiber samples with respect to soaking time is shown in Figure 3. The water absorption curve shows that with the increase of soaking time water absorption increases. The initial rate is faster, but as time elapsed it becomes slower. After first hour fiber absorbs $40.08 \%$ of water of its total increase. Water absorption increases with the soaking time up to 24 hours. After 24 hours the absorption rate of water content tends to become steady as time passes. It is known that banana fiber contains $65 \%$ cellulose and it is hydrophilic in nature. Hydrogen bond occurs between the free hydroxyl groups of the cellulosic molecules with water molecule for the increase of soaking rate [36].

\subsubsection{Water Absorption of BF-HDPE Composites}

Water absorption vs soaking time for different wt. (\%) of banana fiber in continuous aligned BF-HDPE composites samples has shown in Figure 4. Percentage of water absorption increases with the increase of wt. (\%) of fiber content in composites also with time. Water may penetrate into the composite through the cutting/interfacial side of the sample that allowed hydrogen bonding to occur between the free hydroxyl groups of the cellulosic molecules with water molecule [36]. Water absorption rate is very fast within the initial 24 hours and then the absorption rate becomes almost steady. At later time composites reached a constant water uptake beyond which water exists as free water in the void structure and does not contribute to further expansion [37]. In two different fiber orientation samples were made for this research (continuous aligned fiber orientation

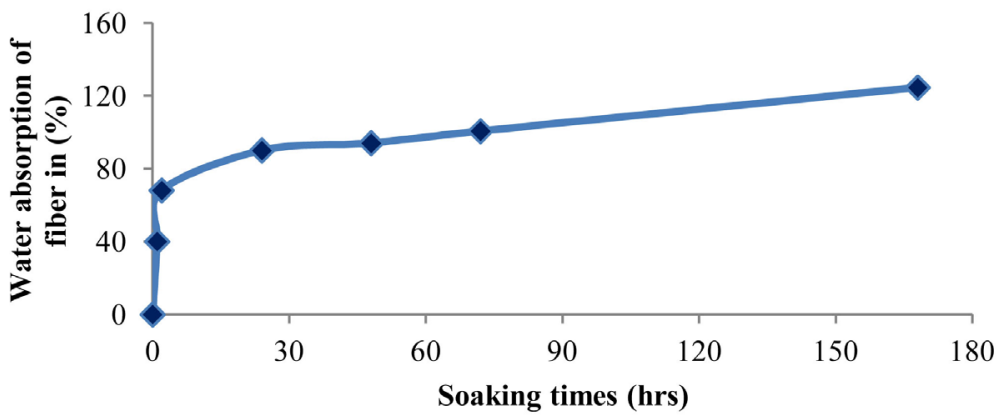

Figure 3. Water absorption vs soaking time curve for banana fiber.

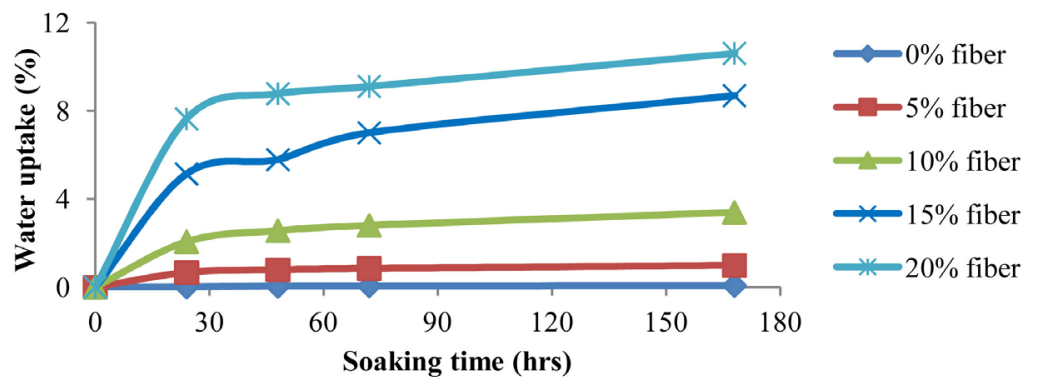

Figure 4. Water absorption (\%) vs soaking time (hrs) for different wt. (\%) fiber content in continuous aligned BF-HDPE composites. 
and continuous bidirectional fiber orientation). For bulk density and water absorption measurements continuous aligned fiber orientation samples were taken because of their better mechanical properties.

\subsection{Mechanical Properties}

\subsubsection{Tensile Strength of BF-HDPE Composites}

The effect of addition of banana fiber on tensile strength in BF-HDPE composites is shown in Figure 5, in which continuous aligned fiber orientation and continuous bidirectional fiber orientation is presented in Figure 5(b) and Figure 5(a), respectively. In each case of 5\%, 10\%, 15\% and 20\% banana fiber-HDPE composite samples, total ten samples were taken for tensile strength calculation. These figures reveal that tensile strength of the BF-HDPE composites increases with the increase of fiber content in both orientation of fiber in composites. The results are summarized in Table 1 for tensile strength and Young's modulus of two different fiber orientations.

Moreover, a comparative study of the tensile strength of BF-HDPE composites with continuous aligned fiber orientation and continuous bidirectional fiber orientation shown in Figure 6. It is found from this figure that the tensile strength of BF-HDPE composites with continuous aligned fiber orientation is much greater than that of continuous bidirectional fiber orientation. For continuous aligned fiber orientation the percentage of change of the tensile strength

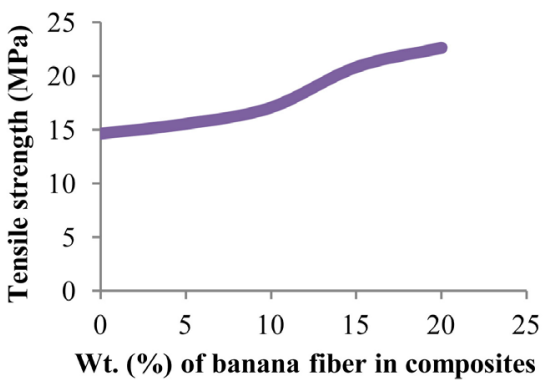

(a)

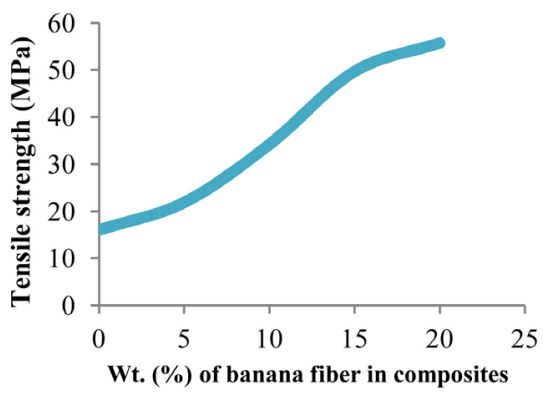

(b)

Figure 5. Tensile strength of BF-HDPE composites for different wt. (\%) fiber content (a) continuous bidirectional fiber orientation, (b) continuous aligned fiber orientation.

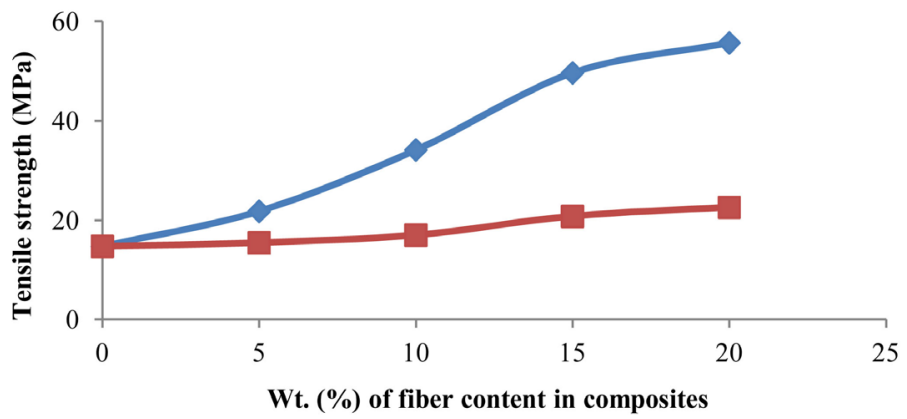

Figure 6. Comparison of tensile strength vs wt. (\%) of banana fiber in composites for two different fiber orientation (Here blue curve for continuous aligned fiber orientation and red curve for continuous bidirectional fiber orientation). 
Table 1. Tensile strength of BF-HDPE composites for different wt. (\%) of fiber content in two orientations.

\begin{tabular}{ccccc}
\hline \multirow{2}{*}{$\begin{array}{c}\text { Wt. (\%) of fiber } \\
\text { in composite }\end{array}$} & \multicolumn{2}{c}{$\begin{array}{c}\text { Continuous aligned } \\
\text { fiber orientation }\end{array}$} & \multicolumn{2}{c}{$\begin{array}{c}\text { Continuous bidirectional } \\
\text { fiber orientation }\end{array}$} \\
\cline { 2 - 5 } & $\begin{array}{c}\text { Tensile strength } \\
(\mathrm{MPa})\end{array}$ & $\begin{array}{c}\text { Young's modulus } \\
(\mathrm{GPa})\end{array}$ & $\begin{array}{c}\text { Tensile strength } \\
(\mathrm{MPa})\end{array}$ & $\begin{array}{c}\text { Young's modulus } \\
(\mathrm{GPa})\end{array}$ \\
\hline 0 & 14.76 & 130.58 & 14.76 & 130.58 \\
5 & 21.83 & 408.50 & 15.51 & 214.77 \\
10 & 34.14 & 499.47 & 17.03 & 316.98 \\
15 & 49.66 & 566.33 & 20.8 & 357.58 \\
20 & 55.7 & 822.0 & 22.6 & 413.49 \\
\hline
\end{tabular}

with respect to $0 \%$ fiber are $47.9 \%$ (for $5 \%$ ), $131.30 \%$ (for $10 \%$ ), $236.45 \%$ (for $15 \%$ ) and $277.37 \%$ (for 20\%) whereas these values for continuous bidirectional fiber orientation with respect to $0 \%$ fiber are $5.08 \%$ (for $5 \%$ ), $15.38 \%$ (for $10 \%$ ), $40.92 \%$ (for $15 \%$ ) and $53.12 \%$ (for $20 \%$ ).

The maximum value of the tensile strength of banana fiber reinforced HDPE composites is found to be $55.7 \mathrm{MPa}$ for $20 \mathrm{wt} \%$ banana fiber composite. This may be due to the fact that the fibers are well distributed and the better interfacial bonding between the fiber and matrix. Another study reported that the fibers disperse poorly when reinforced into thermoplastic matrices due to strong inter fiber hydrogen bonding which holds the fibers together [38].

\subsubsection{Flexural Strength of BF-HDPE Composites}

The effect of fiber loading on flexural strength for two different fiber orientations in BF-HDPE composites is shown in Figure 7. In each case of 5\%, 10\%, $15 \%$ and $20 \%$ BF-HDPE composite samples, total ten samples were taken for flexural strength calculation. Figure revealed that flexural strength of the BF-HDPE composites increases with the increase of fiber content for $5 \%$ and then it decreases for $10 \%, 15 \%$ and $20 \%$ fiber content composites.

Previous research showed that natural fiber has poor wettability, incompatibility with some polymeric matrices and high moisture absorption, and for the reason of high moisture absorption properties, there are formations of void in the composites which can reduce the mechanical properties of composite such as flexural strength [39] [40]. Moreover, the flexural strength of banana fiber-HDPE composites with continuous aligned fiber orientation is slightly greater than that of continuous bidirectional fiber orientation. Shinichi et al. have investigated the effects of the volume fraction and lengths of natural fibers on flexural properties of biodegradable composites [41]. Kenaf and bagasse were mixed with corn-starch biodegradable resin, and composite flexural specimens were fabricated by press forming. The flexural modulus of the natural fiber composite made from Kenaf and bagasse increased, with an increase in fiber volume fraction up to $60 \%$ for Kenaf, and up to $66 \%$ for bagasse. Above these percentages of Kenaf and bagasse, the composite shows weak properties. 


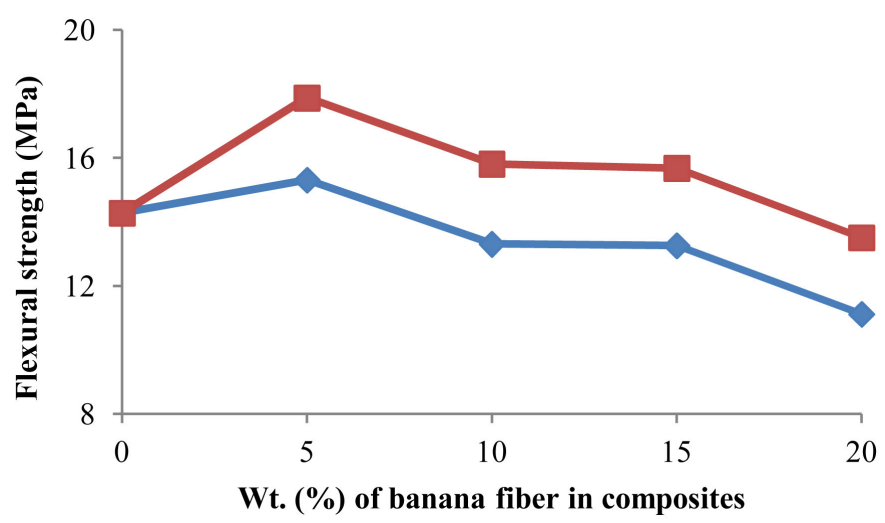

Figure 7. Flexural strength vs wt. (\%) of banana fiber in composites for two different fiber orientation (Here red curve represents continuous aligned fiber orientation and blue curve for continuous bidirectional fiber orientation).

\subsubsection{Leeb's Rebound Hardness of BF-HDPE Composites}

The effect of addition of banana fiber on Leeb's rebound hardness for different wt. (\%) of banana fiber in BF-HDPE composites is presented in Figure 8. This figure shows the change of hardness with different wt. (\%) of fiber for two different fiber orientation such as continuous aligned fiber orientation and continuous bidirectional fiber orientation. It is observed that at first Leeb's rebound hardness increase for 5\% BF-HDPE composites then the value decrease for $10 \%$, $15 \%$ and 20\% BF-HDPE composite samples as shown in Figure 8. Tan et al. showed that due to high moisture absorption properties, there are formation of void in the composites which can reduce the mechanical properties of composite such as hardness [42].

Bhuiyan, A. H. et al. showed that with the inclusion of $\mathrm{TiO}_{2}$, the hardness of the composites decreased [43]. This research concluded that the composite materials were somewhat soften by the addition of filler. Rahman, M. M. et al. showed that natural fibers absorb moisture content due to its strong hydrophilic natures which in turns degrade the mechanical properties of natural fiber reinforced composite [44]. Leeb's Rebound Hardness values for different wt. (\%) of fiber content in BF-HDPE composites for two different fiber orientations are summarized in Table 2.

\subsection{Thermal Properties}

Thermogravimetric analysis (TGA) has accomplished to observe the thermal stability of obsolete HDPE and BF-HDPE composites. The TG/DTA scans of BF-HDPE composites were taken in nitrogen atmosphere (at a flow of 100 $\mathrm{ml} / \mathrm{min}$ ) using a TG/DTA 6300 system controlled by an EXSTAR 6000 controller (SEIKO Instruments Inc., Japan) [45]. The TG/DTA module has a horizontal system balance mechanism. Alumina was used as reference material and furnace temperature was programmed by software controlled converter.

The TG/DTA measurement was done by using small portions (of about 2 - 5 mg from each sample) of the sample cutting from the composites by using 


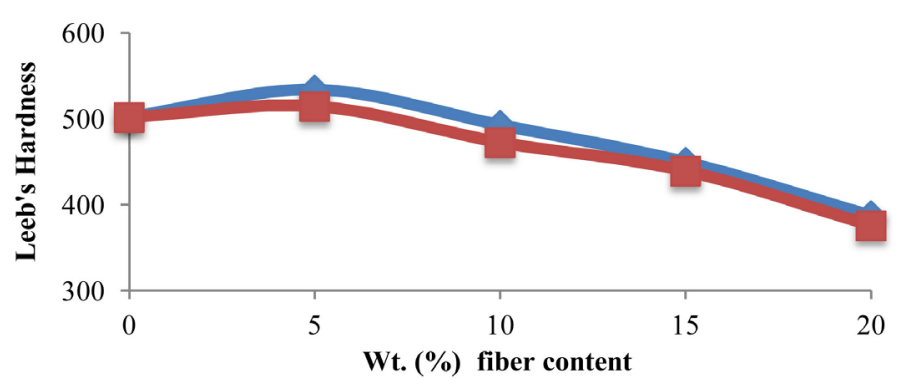

Figure 8. Leeb's Rebound Hardness vs wt. (\%) of banana fiber in composites for two different fiber orientation (Here blue curve for continuous aligned fiber orientation and red curve for continuous bidirectional fiber orientation).

Table 2. Leeb's Rebound Hardness for different wt. (\%) of fiber content in BF-HDPE composites.

\begin{tabular}{ccc}
\hline $\begin{array}{c}\text { Wt.(\%) of fiber } \\
\text { in composites }\end{array}$ & $\begin{array}{c}\text { Hardness for continuous } \\
\text { aligned fiber orientation }\end{array}$ & $\begin{array}{c}\text { Hardness for continuous } \\
\text { bidirectional fiber orientation }\end{array}$ \\
\hline $0 \%$ & 502 & 502 \\
$5 \%$ & 534.11 & 514.83 \\
$10 \%$ & 492.99 & 472.77 \\
$15 \%$ & 449.83 & 439.50 \\
$20 \%$ & 387.78 & 376.03 \\
\hline
\end{tabular}

hacksaw blade. The samples were as like as powder and samples were charred at about $20^{\circ} \mathrm{C} / \mathrm{min}$ to a temperature of $600^{\circ} \mathrm{C}$. Differential thermal parameters such as maximum degradation temperature, onset temperature of major degradation, phase transition temperature and mass loss at various temperature stages were obtained by analyzing the recorded profile with the software.

Figures 9(a)-(e) shows TG/DTG and DTA curves for pure HDPE and BF-HDPE composites for different wt. (\%) of fiber content in composites. In all cases samples taken from continuous aligned fiber orientation method because of their better mechanical properties. In all these curves top one (blue) is the TG, the bottom one (red) is the DTG and the middle one (green) is the DTA curve. The summary of TG, DTG and DTA curve from Figure 9(a) and Figure 9(b) is presented in Table 3.

TG, DTA and DTG curves of obsolete HDPE are shown in Figure 9(a). The TG curve shows an initial loss of $1.1 \%$ which corresponds to moisture content. From TG curve, major degradation stage spans over $455.9^{\circ} \mathrm{C}-491.7^{\circ} \mathrm{C}$ which may be due to decomposition and polymerization of HDPE and corresponding weight loss $91.7 \%$. The onset temperature is $455.9^{\circ} \mathrm{C}$ and $50 \%$ degradation occurs at $473.9^{\circ} \mathrm{C}$ DTA curve shows two endothermic peaks at $139.1^{\circ} \mathrm{C}$ and $481.2^{\circ} \mathrm{C}$. The DTG curve shows peak at $480.6^{\circ} \mathrm{C}$ with degradation rate of $5.07 \mathrm{mg} / \mathrm{min}$.

TG, DTA and DTG curves of 5\% BF-HDPE composite shown in Figure 9(b). TG curve shows that major degradation occurs in single steps and major degradation stage spans over $453.5^{\circ} \mathrm{C}-490.5^{\circ} \mathrm{C}$, which may be due to decomposition 


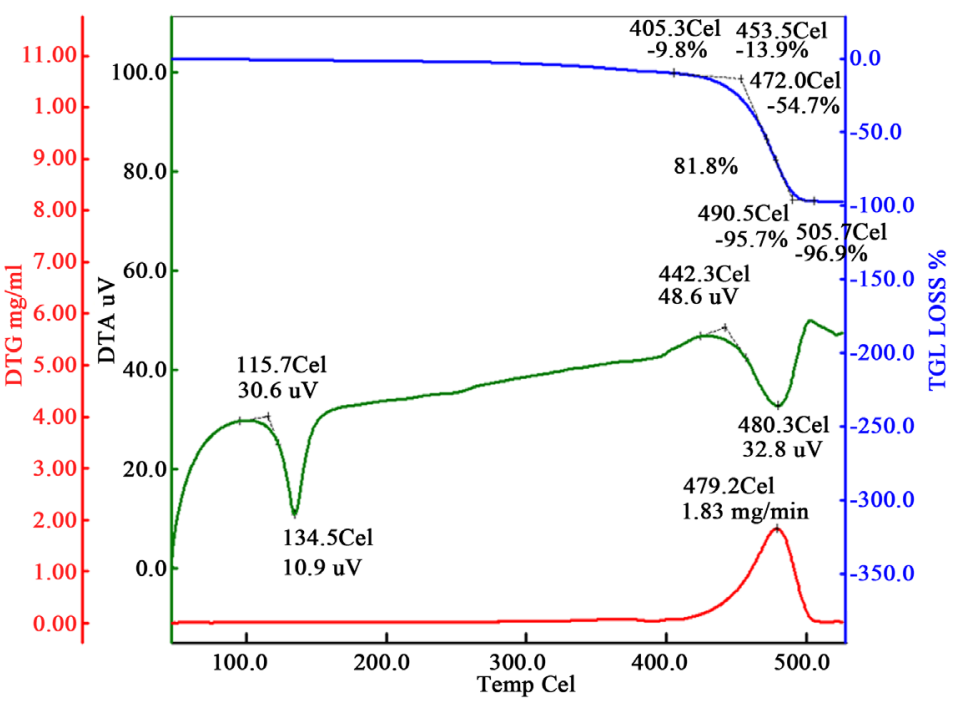

(a)

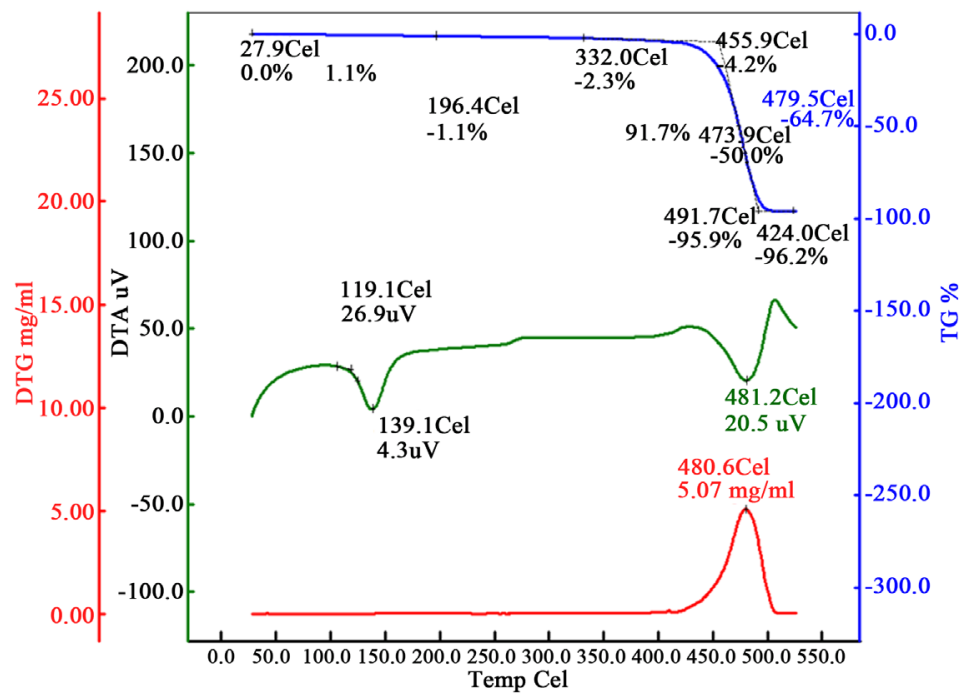

(b)

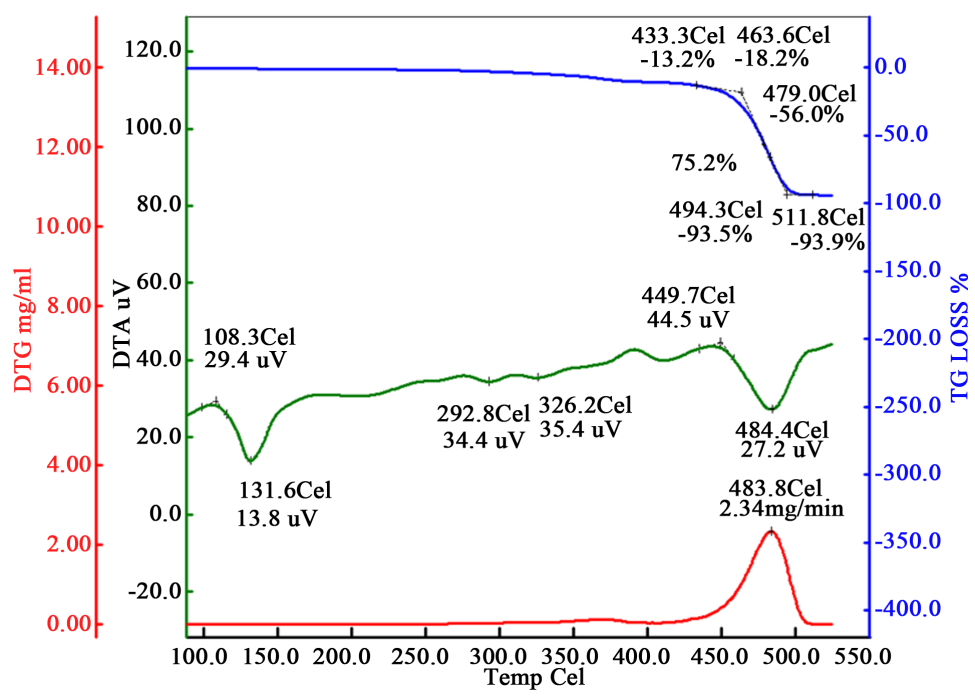

(c) 


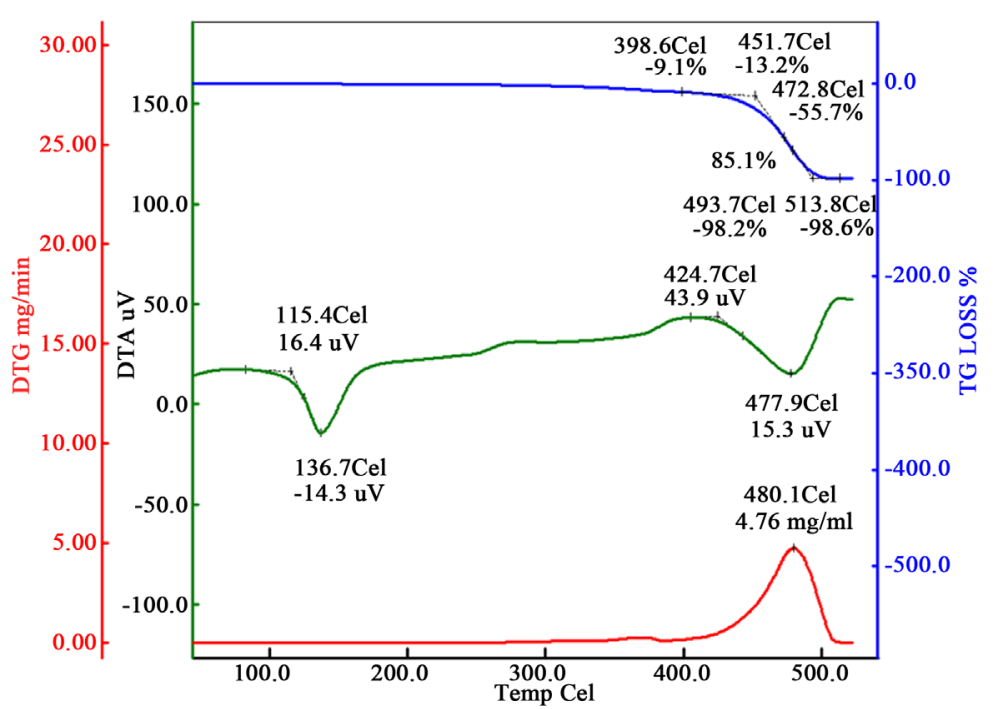

(d)

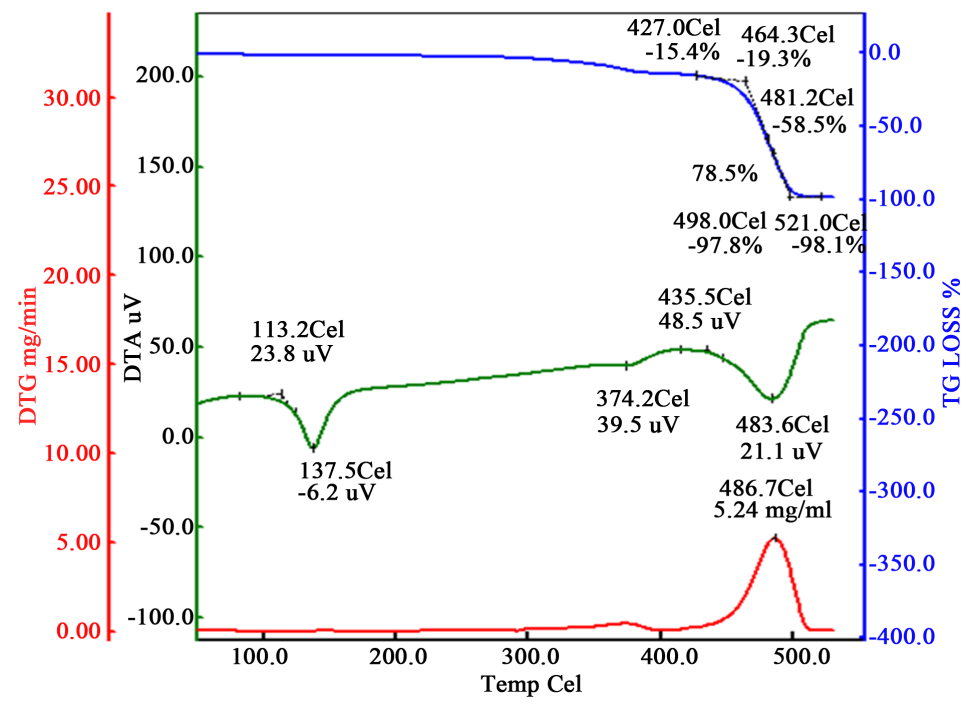

(e)

Figure 9. (a) TG/DTG and DTA curves for obsolete HDPE; (b) TG/DTG and DTA curves for 5\% BF-HDPE composites; (c) TG/DTG and DTA curves for 10\% BF-HDPE composites; (d) TG/DTG and DTA curves for 15\% BF-HDPE composites; (e) TG/DTG and DTA curves for $20 \%$ BF-HDPE composites.

Table 3. Summary of thermal data for obsolete HDPE, BF-HDPE composites for different wt. (\%) of banana fiber content.

\begin{tabular}{cccccc}
\hline Sample no. & Onset temp $/{ }^{\circ} \mathrm{C}$ & Max slope $/{ }^{\circ} \mathrm{C}$ & DTA peak $/{ }^{\circ} \mathrm{C}$ & DTG peak $/{ }^{\circ} \mathrm{C}$ & $\begin{array}{c}\text { Max. deg rate } \\
(\mathrm{mg} / \mathrm{min})\end{array}$ \\
\hline Obsolete HDPE & 455.9 & 479.5 & $139.1,481.2$ & 480.6 & 5.07 \\
$5 \%$ BF-HDPE & 453.5 & 472.0 & $134.5,480.2$ & 479.2 & 1.83 \\
$10 \%$ BF-HDPE & 451.7 & 472.8 & $136.7,477.9$ & 480.1 & 4.76 \\
$15 \%$ BF-HDPE & 463.6 & 479.8 & $131.6,484.4$ & 483.8 & 2.34 \\
20\% BF-HDPE & 464.3 & 481.2 & $137.5,483.6$ & 486.7 & 5.24 \\
\hline
\end{tabular}


and polymerization of HDPE. The onset temperature and maximum slope are $453.5^{\circ} \mathrm{C}$ and $472.0^{\circ} \mathrm{C}$. Total weight loss is $81.8 \%$. DTA curve shows two endothermic peaks at $134.5^{\circ} \mathrm{C}$ and $480.2^{\circ} \mathrm{C}$. The DTG curves shows peak at $479.2^{\circ} \mathrm{C}$ with degradation rate of $1.83 \mathrm{mg} / \mathrm{min}$.

TG, DTA and DTG curves of $10 \%$ banana fiber-HDPE composite is shown in Figure 9(c). TG curve shows the mass loss event occurs mainly in one stage which is due to polymer degradation, major degradation stage spans over $451.7^{\circ} \mathrm{C}-493.7^{\circ} \mathrm{C}$ which may be due to decomposition and polymerization of HDPE. The onset temperature and maximum slope are $451.7^{\circ} \mathrm{C}$ and $472.8^{\circ} \mathrm{C}$. Total weight loss is $85.1 \%$. DTA curve shows two endothermic peaks at $136.7^{\circ} \mathrm{C}$ and $477.9^{\circ} \mathrm{C}$. The DTG curves shows peak at $480.1^{\circ} \mathrm{C}$ with degradation rate of $4.76 \mathrm{mg} / \mathrm{min}$.

TG, DTA and DTG curves of $15 \%$ banana fiber-HDPE composite is shown in Figure 9(d). TG curve shows that the major degradation occurs in single step, major degradation stage spans over $463.6^{\circ} \mathrm{C}-494.3^{\circ} \mathrm{C}$ which may be due to decomposition and polymerization of HDPE. The onset temperature and maximum slope are $463.6^{\circ} \mathrm{C}$ and $479.8^{\circ} \mathrm{C}$.

Total degradation loss is $75.2 \%$. DTA curve shows two prominent endothermic peaks at $131.6^{\circ} \mathrm{C}$ and $484.4^{\circ} \mathrm{C}$. The DTG curves shows peak at $483.8^{\circ} \mathrm{C}$ with degradation rate of $2.34 \mathrm{mg} / \mathrm{min}$.

TG, DTA and DTG curves of $20 \%$ banana fiber-HDPE composite are also shown in Figure 9(e). TG curve shows that major degradation occurs in single step, major degradation stage spans over $464.3^{\circ} \mathrm{C}-498.0^{\circ} \mathrm{C}$ which may be due to decomposition and polymerization of HDPE. The onset temperature and maximum slope are $464.3^{\circ} \mathrm{C}$ and $481.2^{\circ} \mathrm{C}$. The total degradation loss is $78.5 \%$. DTA curve shows two endothermic peaks at $137.5^{\circ} \mathrm{C}$, and $483.6^{\circ} \mathrm{C}$. The DTG curves shows peak at $486.7^{\circ} \mathrm{C}$ with degradation rate of $5.24 \mathrm{mg} / \mathrm{min}$.

All these TG curves show that the mass loss event occurs mainly in one stage which is due to polymer degradation. There is no distinguishable peak for fiber decomposition. Because banana fiber decompose in two stages; decomposition starts around $320^{\circ} \mathrm{C}$ and completed at $450^{\circ} \mathrm{C}$ [46]. But there is no peak at this temperature range in TG, DTG and DTA curves. Thermal degradation temperature for virgin high-density polyethylene (HDPE) is at a temperature range of $400^{\circ} \mathrm{C}$ to $550^{\circ} \mathrm{C}$ [47]. DTA curves show a peak initially and this peak may be for moisture content in composites. Second peak is for thermal degradation of HDPE because it is nearly decomposition temperature of HDPE. From all these curves of BF-HDPE composites it is clear that polymer is the dominating character.

In composites, fibers act as initial source of ignition, but it is not apparent in these composites. The major degradation is due to decomposition of HDPE which is supported by the final endothermic event on DTA and DTG curve. The mass loss and maximum degradation rate depend on the percentage of banana fiber in BF-HDPE composites. Decomposition temperature slightly increases with the increase of wt. (\%) of banana fiber in BF-HDPE composites for 15\% 
and $20 \%$ fiber content composites.

\section{Conclusion}

The physical, mechanical and thermal properties of banana fiber-HDPE composites were performed to investigate the change of different properties due to addition of banana fiber in BF-HDPE composites. Composites were made by hot press molding method by using Paul-Otto Weber Hydraulic press machine. The bulk density of banana fiber in BF-HDPE composites increased with the addition of fiber content in composites because the fiber density is higher than HDPE. Because of hydrophilic nature of banana fiber, water absorption ability of both banana fiber and BF-HDPE composites increased with socking time for a certain period of time. In BF-HDPE composites water absorption also increased with the increase of fiber content. Tensile strength and Young's modulus of the BF-HDPE composites increases with the increase of fiber content in both cases (continuous aligned fiber orientation and continuous bidirectional fiber orientation). And the tensile strength and Young's modulus of BF-HDPE composites with continuous aligned fiber orientation is much greater than that of continuous bidirectional fiber orientation. BF-HDPE composite with $5 \%$ banana fiber showed better flexural property. Then flexural strength decreases with the increase of fiber addition. The flexural strength of continuous aligned fiber orientation was slightly greater than that of continuous bidirectional fiber orientation. Leeb's rebound hardness decreased with the increase of fiber addition in BF-HDPE composites. Different thermal properties like TG/DTG, DTA of the obsolete HDPE and BF-HDPE composites for different wt. (\%) of fiber content were studied using thermo gravimetric analyzer. BF-HDPE composite with $20 \%$ fiber content was more thermally stable than three other compositions. For this reason, 20\% BF-HDPE composites showed the better mechanical properties like tensile strength.

\section{Conflicts of Interest}

The authors declare no conflicts of interest regarding the publication of this paper.

\section{References}

[1] Nayak, N.V. (2014) Composite Materials in Aerospace Applications. International Journal of Scientific and Research Publication, 4, 2250-3153.

[2] Puttegowda, M., Rangappa, S.M., Jawaid, M., Shivanna, P., Basavegowda, Y. and Saba, N. (2018) Potential of Natural/Synthetic Hybrid Composites for Aerospace Applications. Elsevier Ltd., Amsterdam. https://doi.org/10.1016/B978-0-08-102131-6.00021-9

[3] Jawaid, M. and Abdul Khalil, H.P.S. (2011) Cellulosic/Synthetic Fibre Reinforced Polymer Hybrid Composites: A Review. Carbohydrate Polymers, 86, 1-18. https://doi.org/10.1016/j.carbpol.2011.04.043

[4] Vijaya Ramnath, B., et al. (2013) Evaluation of Mechanical Properties of Ab- 
aca-Jute-Glass Fibre Reinforced Epoxy Composite. Materials \& Design, 51, 357-366. https://doi.org/10.1016/j.matdes.2013.03.102

[5] Yan, L., Chouw, N. and Jayaraman, K. (2014) Flax Fibre and Its Composites: A Review. Composites Part B: Engineering, 56, 296-317.

https://doi.org/10.1016/j.compositesb.2013.08.014

[6] Gupta, M.K. and Srivastava R.K. (2015) Effect of Sisal Fibre Loading on Dynamic Mechanical Analysis and Water Absorption Behaviour of Jute Fibre Epoxy Composite. Materials Today: Proceedings, 2, 2909-2917.

https://doi.org/10.1016/j.matpr.2015.07.253

[7] Manickavasagam, V.M., et al. (2015) Investigation of Tensile Behaviour of Flax-Abaca Hybrid Epoxy Composite. Applied Mechanics and Materials, 766-767, 140-143. https://doi.org/10.4028/www.scientific.net/AMM.766-767.140

[8] Akter, R., Sultana, R. and Alam, Z. (2013) Fabrication and Characterization of Woven Natural Fibre Reinforced Unsaturated Polyester Resin Composites. International Journal of Engineering and Technology, 3, 122-128.

[9] Ratna Prasad, A.V. and Mohana Rao, K. (2011) Mechanical Properties of Natural Fibre Reinforced Polyester Composites: Jowar, Sisal and Bamboo. Materials \& Design, 32, 4658-4663. https://doi.org/10.1016/j.matdes.2011.03.015

[10] Durowaye, S.I., Lawal, G.I. and Olagbaju, O.I. (2014) Microstructure and Mechanical Properties of Sisal Particles Reinforced Polypropylene Composite. International Journal of Composite Materials, 2014, 190-195.

[11] Asgekar, S.D., Joshi, V.K., Futane, P.S. and Joshi, P.S. (2013) Characteristics of Sugarcane/Coir Fibres Reinforced Composites in Phenol Formaldehyde Resin. International Journal of Composite Materials, 3, 156-162.

[12] Khan, M.A. and Bhattacharia, S.K. (2007) Effect of Novel Coupling Agent on the Mechanical and Thermal Properties of Unidirectional Jute-Vinyl Ester Composites. The Journal of Reinforced Plastics and Composites, 26, 617-627. https://doi.org/10.1177/0731684407075563

[13] Jahan, A., et al. (2017) Optical, Electrical and Thermal Properties of Jute and Glass Fiber Reinforced LDPE Composites. International Journal of Basic \& Applied Sciences, 1, 482-490. https://doi.org/10.17142/ijbas-2012.1.3.3

[14] Aleya Fardausy, M.A.G., Kabir, A., Kabir, H., Rahman, M.M., Begam, K., Ahmed, F. and Hossain, A. (2012) Study of Physical, Mechanical and Thermal Properties of Unidirectional Jute Fiber Reinforced Pvc Film Composites. International Journal of Advanced Research in Science, Engineering and Technology, 3, 267-274.

[15] Kabir, H., Gafur, A., Ahmed, F., Begum, F. and Qadir, R. (2014) Investigation of Physical and Mechanical Properties of Bamboo Fiber and PVC Foam Sheet Composites. Universal Journal of Materials Science, 2, 119-124.

[16] Muthukumar, A. and Veerappapillai, S. (2015) Biodegradation of Plastics: A Brief Review. International Journal of Pharmaceutical Sciences Review and Research, 31, 204-209.

[17] Industrial Applications of Natural Fibres (2010)

[18] Pathania, D., Singh, D. and Sharma, D. (2010) Electrical Properties of Natural Fiber Graft Co-Polymer Reinforced Phenol Formaldehyde Composites. Optoelectronics and Advanced Materials. Rapid Communications, 4, 1048-1051.

[19] Chianelli-Junior, R., Reis, J.M.L., Cardoso, J.L. and Castro, P.F. (2013) Mechanical Characterization of Sisal Fiber-Reinforced Recycled HDPE Composites. Materials Research, 16, 1393-1397. https://doi.org/10.1590/S1516-14392013005000128 
[20] Ibrahim, M.M., Dufresne, A., El-Zawawy, W.K. and Agblevor, F.A. (2010) Banana Fibers and Microfibrils as Lignocellulosic Reinforcements in Polymer Composites. Carbohydrate Polymers, 81, 811-819. https://doi.org/10.1016/j.carbpol.2010.03.057

[21] Khan, M.A., et al. (2010) Thermal, Mechanical and Morphological Characterization of Jute/Gelatin Composites. Polymer-Plastics Technology and Engineering, 49, 742-747. https://doi.org/10.1080/03602551003652698

[22] Roumeli, E., et al. (2015) Effect of Maleic Anhydride on the Mechanical and Thermal Properties of Hemp/High-Density Polyethylene Green Composites. Journal of Thermal Analysis and Calorimetry, 121, 93-105. https://doi.org/10.1007/s10973-015-4596-y

[23] Mustata, F.S.C., Tudorachi, N., Mustata, A. and Mustata, F. (2015) Physical and Thermal Characterization of Some Cellulose Fabrics as Reinforced Materials for Composite. Journal of Thermal Analysis and Calorimetry, 120, 1703-1714. https://doi.org/10.1007/s10973-015-4521-4

[24] Naznin, M., Abedin, M.Z., Khan, M.A. and Gafur, M.A. (2012) Influence of Acacia catechu Extracts and Urea and Gamma Irradiation on the Mechanical Properties of Starch/PVA-Based Material . ISRN Polymer Science, 2012, 1-8. https://doi.org/10.5402/2012/348685

[25] Ozalp, M. (2011) Study of the Effect of Adding the Powder of Waste PET Bottles and Borax Pentahydrate to the Urea Formaldehyde Adhesive Applied on Plywood. European Journal of Wood and Wood Products, 69, 369-374. https://doi.org/10.1007/s00107-010-0439-5

[26] HDPE (High Density Polyethylene). http://www.upcinc.com/resources/materials/HDPE.html

[27] Albert, F. (1952) Hill, Economic Botany. 2nd Edition, McGraw-Hill, New York.

[28] High Density Polyethylene (HDPE) Bottles Suppliers. http://www.thomasnet.com/products/high-density-polyethylene-hdpe-bottles-9619 7330-1.html

[29] ASTM C134-95 (2016) Standard Test Methods for Size, Dimensional Measurements and Bulk Density of Refractory Brick and Insulating Firebrick. ASTM International, West Conshohocken, PA.

[30] ASTM D570-98 (2018) Standard Test Method for Water Absorption of Plastics. ASTM International, West Conshohocken, PA.

[31] Standard Test Method for Tensile Properties of Polymer Matrix Composite Materials (2014) Standard Test Method for Tensile Properties of Polymer Matrix Composite Materials. Annual Book of ASTM Standards, 1-13.

[32] ASTM D6272-17 (2017) Standard Test Method for Flexural Properties of Unreinforced and Reinforced Plastics and Electrical Insulating Materials by Four-Point Bending. ASTM International, West Conshohocken, PA.

[33] Kablov, E.N., Grashchenkov, D.V., Isaeva, N.V., Solntsev, S.S. and Sevast'Yanov, V.G. (2012) Glass and Ceramics Based High-Temperature Composite Materials for Use in Aviation Technology. Glass Ceramics, 69, 109-112. https://doi.org/10.1007/s10717-012-9425-1

[34] TGA Analysis or Thermogravimetric Analysis. http://www.andersonmaterials.com/tga.html

[35] Malič B., Kupec A. and Kosec M. (2013) Thermal Analysis. In: Chemical Solution Deposition of Functional Oxide Thin Films, Springer, Berlin, 163-179. https://doi.org/10.1007/978-3-211-99311-8_7 
[36] Khan, J.A., Khan, M.A., Islam, R. and Gafur, A. (2010) Mechanical, Thermal and Interfacial Properties of Jute Fabric-Reinforced Polypropylene Composites: Effect of Potassium Dichromate. Materials Sciences and Applications, 1, 350-357. https://doi.org/10.4236/msa.2010.16051

[37] Handbook of Fiber Chemistry. (2006)

[38] Lima, A.C., Monteiro, S.N. and Satyanarayana, K.G. (2012) Recycled Polyethylene Composites Reinforced with Jute Fabric from Sackcloth: Part I-Preparation and Preliminary Assessment. Journal of Polymers and the Environment, 20, 245-253. https://doi.org/10.1007/s10924-011-0373-6

[39] Taj, S., Munawar, M.A. and Khan, S. (2007) Natural Fiber-Reinforced Polymer Composites Natural Fiber-Reinforced Polymer Composites. Pakistan Academy of Science, 44, 129-144. https://doi.org/10.1533/9781845695057.129

[40] Mohammad, N.N.B. and Arsad, A. (2013) Mechanical, Thermal and Morphological Study of Kenaf Fibre Reinforced RPET/ABS Composites. Malaysian Polymer Journal, 8, 8-13.

[41] Shinichi, S., Isao, F. and Yong, C. (2006) Effects of Fiber Compression and Length Distribution on the Flexural Properties of Short Kenaf Fiber-Reinforced Biodegradable Composites. Polymer Composites, 27, 170-176.

https://doi.org/10.1002/pc.20205

[42] Tan, C., Ahmad, I. and Heng, M. (2011) Characterization of Polyester Composites from Recycled Polyethylene Terephthalate Reinforced with Empty Fruit Bunch Fibers. Materials \& Design, 32, 4493-4501. https://doi.org/10.1016/j.matdes.2011.03.037

[43] Bhuiyan, A.H., Mina, M.F., Seema, S., Khan, M.M., Rahman, M.J. and Gafur, M.A. (2011) Structural, Elastic and Thermal Properties of Titanium Dioxide Filled Isotactic Polypropylene. Journal of Polymer Research, 18, 1073-1079. https://doi.org/10.1007/s10965-010-9509-y

[44] Rahman, M.M. and Khan, M.A. (2007) Surface Treatment of Coir (Cocos nucifera) Fibers and Its Influence on the Fibers' Physico-Mechanical Properties. Composites Science and Technology, 67, 2369-2376. https://doi.org/10.1016/j.compscitech.2007.01.009

[45] Hatakeyama, H., Ohsuga, T. and Hatakeyama, T. (2014) Thermogravimetry on Wood Powder-Filled Polyurethane Composites Derived from Lignin. Journal of Thermal Analysis and Calorimetry, 118, 23-30. https://doi.org/10.1007/s10973-014-3959-0

[46] Decomposition of Banana Fiber. http://shodhganga.inflibnet.ac.in/bitstream/10603/22438/16/16_chapter4.pdf

[47] Kumar, S. and Singh, R.K. (2013) Thermolysis of High-Density Polyethylene to Petroleum Products. Journal of Petroleum Engineering \& Technology, 2013, 1-7. https://doi.org/10.1155/2013/987568 